\title{
Subject Status Domain
}

National Cancer Institute

\section{Source}

National Cancer Institute. Subject Status Domain. NCI Thesaurus. Code C117655.

A subject domain utilized for the submission of information encompassing and representing data, vocabulary or records related to subject status. 